\title{
Perceived barriers of, and benefits to, healthy eating reported by a Spanish national sample
}

\author{
Isabel López-Azpiazu', Miguel Ángel Martínez-González² , John Kearney³, \\ Michael Gibney ${ }^{3}$ and J. Alfredo Martínez ${ }^{1, *}$ \\ 'Department of Physiology and Nutrition, University of Navarra, Pamplona, Spain: ${ }^{2}$ Department of \\ Epidemiology and Public Health, University of Navarra, Pamplona, Spain: ${ }^{3}$ Institute for European Food Studies, \\ Dublin, Ireland
}

Submitted 5 May 1998: Accepted 25 September 1998

\begin{abstract}
Objective: A national survey was developed in order to assess the difficulties and the potential benefits that the adult Spanish population perceive when they try to eat a healthier diet and also to help nutrition educators to develop relevant and specific strategies to promote healthy eating.

Design: The study survey was carried out according to an established protocol on a representative sample of 1009 Spanish subjects over 15 years of age selected by a multi-stage procedure. This study belongs to a partnership in a pan-European survey about food, nutrition and health. The analysis was focused on the evaluation of the seven most frequently chosen barriers and benefits.

Results: There was a trend to select as the main barriers: 'irregular work hours' (29.7\%), 'willpower' (29.7\%) and 'unappealing food' (21.3\%), while 'prevent disease' (73.6\%) was the most frequently selected benefit to healthy eating. About $20 \%$ of the subjects said they did not have any difficulty eating healthier and most people believed that healthy eating was associated with at least one benefit.

Conclusions: In Spain, nutrition educators should be aware that an irregular and busy lifestyle, willpower and food-related factors (such as price and unappealing foods) are the main perceived barriers to healthy eating. Conversely, the prevention and health promotion aspects are the main perceived benefits.
\end{abstract}

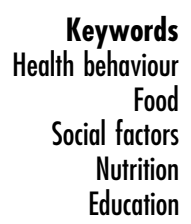

Diet and nutrition are clearly essential determinants of good health, although the contribution of appropriate nutrition to promoting health and preventing disease is difficult to measure ${ }^{1}$. Poor dietary patterns play a role in many leading causes of death and disease in Spain, despite this, Spaniards are perceived as benefiting from a 'healthy Mediterranean' diet, providing fruit, vegetables, fish and olive oil in higher amounts than other Western diets, which has been associated with a lower prevalence of cardiovascular diseases and other with diet-related health problems ${ }^{2,3}$. Furthermore, although there are no official recommendations for healthy eating in Spain, the pyramid pattern is widely accepted $^{2}$. In other countries, several recent trials have shown that modifying dietary habits can reduce the risk of death and several diseases related to dietary habits ${ }^{4}$. There is a wide range of social barriers to changing eating habits such as cost of food, lack of knowledge, limited cooking experience, apathy, dietary conservatism, etc. ${ }^{5}$ In this context, studying the perceived barriers towards, and benefits of, healthy eating may provide a better understanding of the factors that motivate people or prevent them from making changes in their diet ${ }^{6,7}$.

Changing food consumption is not an easy task even for those who have actual personal health reasons for doing so, because people have difficulties relating health with their own lifestyles or personal behaviours ${ }^{8}$. However, from the consumer's point of view there are significant reasons for eating more healthily such as to improve overall health and prevent disease ${ }^{9-11}$. Nevertheless, nutrition educators should know what those benefits are in order to decide whether the general public require any or more information about some of the possible benefits from nutrition guidelines ${ }^{12}$.

The aim of this study was to assess the perceived barriers in trying to eat healthier and to get information about the expected benefits of a healthy diet in the Spanish adult population.

\section{Methods}

A national survey was carried out according to an established protocol on a representative sample of 1009 
Spanish subjects over 15 years of age, according to the standards of the marketing research set out by ICC/ ESOMAR, the European Society for Opinion and Marketing Research. The sample was selected by a multistage procedure to ensure national representativeness ${ }^{13}$. This study belongs to a partnership in a panEuropean survey about attitudes to food, nutrition and health ${ }^{14}$. The survey was integrated in a pan-European project co-ordinated by the Institute of European Food Studies (Dublin). The selection of the sample was aimed to obtain nationally representative samples from each member state ${ }^{15}$. The interviews were conducted as part of Eurobus, an international group of market research organizations. All interviews were completed between October 1995 and February 1996. The selected sampling units were chosen randomly, by a stratified and balanced method according to the population size within each city. Sampling points were randomly chosen from each sampling unit. In the geographical distribution six areas were considered (Nielssen regions): Northeast (Lérida, Baleares, Barcelona and Zaragoza), East (Valencia, Castellón and Alicante), South (Jaén Sevilla, Malaga, Cadiz and Cordoba), Centre (Zamora, Segovia, Ciudad Real Salamanca, Valladolid and Madrid), Northwest (Leon, Orense, Asturias and Pontevedra) and North (Cantabria, Navarra, La Rioja, Alava and Vizcaya). Within cities, individuals were chosen by a random route procedure applying quotas of age and sex, according to the 1991 census data. Only one person per household was interviewed. In cases where more than one person of

Table 1 The 22 barriers to eating healthily which were included in the survey on 1009 Spanish adults on consumer attitudes to food, nutrition and health. Percentages of interviewed individuals mentioning each barrier (\%). A maximum of two choices were offered

\begin{tabular}{lc}
\hline Barrier & $\%$ \\
\hline Irregular work hours & 29.7 \\
Willpower & 24.7 \\
Unappealing food & 21.3 \\
Busy lifestyle & 17.8 \\
Price of healthy foods & 15.6 \\
Giving up foods that I like & 14.3 \\
I don't want to change my eating habits & 12.6 \\
Taste preferences of family or friends & 11.5 \\
Not knowing enough about healthy eating & 8.5 \\
Strange or unusual foods & 7.5 \\
Cooking skills & 7.4 \\
Too great a change from my current diet & 7.4 \\
Lengthy preparation & 6.7 \\
Limited choice when I eat out & 6.6 \\
Not enough food to satisfy hunger & 5.8 \\
'Experts' keep changing their minds & 5.5 \\
Healthy food is more perishable & 5.5 \\
Storage facilities & 4.7 \\
Limited cooking facilities & 4.7 \\
Healthy food more awkward to carry home from shops & 2.0 \\
Feeling conspicuous amongst others & 1.7 \\
No difficulty & 20.6 \\
\hline
\end{tabular}

the family met the quota requirements, only the first eligible subject who came to the door was selected.

Sample size was calculated with the following assumptions: alpha error $=5 \%$, precision $= \pm 3.1 \%$ and $50 \%$ of individuals in the category of interest. Participation rate was $88 \%$. As with any sample of subjects participating in a survey, there was the possibility that non-respondents had different barriers of and benefits to healthy eating from those who took part. Once individuals who did not want to participate were excluded, 1009 Spanish subjects over 15 years of age were interviewed.

Each subject was personally contacted at his/her home by a professional interviewer specifically trained for this study, belonging to a specialized firm developing social surveys. The average duration of each interview was about $15 \mathrm{~min}$.

An expert panel including nutritionists and food behavioural scientists from all member states of the EU and market researchers from industry convened to discuss the barriers to healthy eating included in the survey. Subjects were asked to select two options out of a list with 22 possible barriers chosen by the experts (Table 1). The options 'No difficulty' and 'Other' were also included and barriers in relation to resistance to change, such as 'I don't want to change my eating habits' and 'Not knowing enough about healthy eating'.

About the perceived benefits of healthy eating, two questions were asked. The first question was 'Some people believe that healthy eating has specific benefits, some of which are shown on this card. Which, if any, would you personally believe can be achieved by healthy eating?' (Table 2). People were asked to select their answer from a list with nine items. The second question was "Which one benefit would be the most personally significant for you?' Subjects had to choose only one answer from the list (Table 5).

Social class was analysed according to occupation and was classified into four categories (1, middleupper, professionals; 2 , middle, part-time workers, 3 ,

Table 2 The 12 benefits of healthy eating which were included in the survey on 1009 Spanish adults on consumer attitudes to food, nutrition and health. Percentages of interviewed individuals mentioning each benefit (\%)

\begin{tabular}{lc}
\hline Benefit & $\%$ \\
\hline Prevent disease in general & 73.6 \\
Stay healthy & 69.4 \\
Have a better quality of life & 50.9 \\
Control my weight & 47.0 \\
Be fit & 39.4 \\
Live longer & 28.7 \\
Have plenty of energy & 28.2 \\
Do well at sport & 15.8 \\
Look attractive & 10.7 \\
Healthy options not available in shop or canteen or home & 6.6 \\
None of these & 1.6 \\
Don't know & 1.0 \\
\hline
\end{tabular}


middle-lower, non-manual and manual qualified workers; 4, lower, unemployed and non-qualified workers). Education level was classified into three categories according to the model of the Statistic Bureau of the Regional Government of Madrid in primary, secondary and university level ${ }^{16}$.

The $\chi^{2}$ test for linear trend and the Pearson $\chi^{2}$ test were used $\left({ }^{*} P<0.05,{ }^{* *} P<0.01,{ }^{* * *} P<0.001\right)$ with SPSS software, to assess the effect of demographic variables such as sex, age, educational level, socioeconomic level and employment status on each one. Analyses were weighted to maintain national representativeness.

\section{Results}

\section{Barriers}

Among the 22 reported barriers (see Table 1), the most frequently answered were: 'Irregular work hours' (29.7\%), 'Willpower' (24.7\%), 'Unappealing food' (21.3\%), 'Busy lifestyle' (17.8\%), 'Price of healthy foods' (15.5\%), 'Give up foods' (14.3\%) and 'No difficulty' (20.6\%). Another group of people showed some resistance to change when they answered with opinions like 'I don't want to change my eating habits' (12.6\%) or 'Not knowing enough about healthy eating' (8.5\%).

There were no statistically significant variations due to gender in the percentage of subjects selecting the different barriers about healthy eating. However, more males (27\%) than females (22.5\%) selected 'Willpower' as a difficulty to eating a healthier diet (Table 3 ). There were important variations with age, with younger men more frequently selecting 'Irregular work hours' ( $P=0.002$ for linear trend) and 'Willpower' as the main difficulties to changing their dietary habits. Older people selected more frequently 'No difficulties' to eat healthy.

Regarding educational level, those with the highest level were more likely to mention 'Irregular work hours' and 'Busy lifestyle' as the main barriers to healthier eating, while those individuals with a primary education associated more often 'Unappealing foods' with a better diet in nutritional terms.

The percentage of subjects who selected 'Unappealing food' and 'Price of healthy foods' as their main difficulties to eating a healthier diet increased in the lowest socioeconomic levels. By contrast, as the socioeconomic level of respondents increased, so did the percentage of those who mentioned 'Irregular work hours' and 'Busy lifestyle'. 'Willpower' was the most commonly mentioned problem by unemployed people (37.6\%), while for those who were working, time ('Irregular work hours') was the main barrier to healthy eating.

\section{Benefits}

Among the nine benefits statements included in the survey (see Table 2), the most frequently selected were:

Table 3 Perceived barriers to healthy eating by Spanish subjects (\%) classified by sex, age group, education level, socioeconomic level and employment status

\begin{tabular}{|c|c|c|c|c|c|c|c|}
\hline & $\begin{array}{l}\text { Irregular } \\
\text { work hours }\end{array}$ & Willpower & $\begin{array}{l}\text { Unappealing } \\
\text { food }\end{array}$ & $\begin{array}{l}\text { Busy } \\
\text { lifestyle }\end{array}$ & $\begin{array}{c}\text { Price of } \\
\text { healthy foods }\end{array}$ & $\begin{array}{l}\text { Give up } \\
\text { foods }\end{array}$ & No difficulty \\
\hline \multicolumn{8}{|l|}{ Sex } \\
\hline Male & 29.6 & 27.0 & 20.9 & 17.6 & 14.1 & 13.4 & 20.0 \\
\hline Female & 29.8 & 22.5 & 21.6 & 18.0 & 17.0 & 15.0 & 21.1 \\
\hline \multicolumn{8}{|l|}{ Age (years) } \\
\hline $15-34$ & $36.4^{\star *}$ & 30.4 & 25.2 & 21.6 & 15.7 & 15.2 & 14.3 \\
\hline $35-54$ & 39.0 & 22.4 & 16.6 & 20.4 & 20.1 & 14.9 & 17.4 \\
\hline$>55$ & 26.8 & 22.8 & 18.3 & 13.8 & 16.4 & 12.1 & 25.3 \\
\hline \multicolumn{8}{|l|}{ Educational level } \\
\hline Primary & 22.0 & 22.5 & $23.9^{* *}$ & 13.8 & 14.6 & 14.8 & $24.1^{* *}$ \\
\hline Secondary & 41.6 & 32.5 & 17.4 & 20.9 & 17.1 & 14.9 & 13.2 \\
\hline University & $48.8^{\star \star \star}$ & 23.3 & 14.3 & $32.5^{\star \star \star}$ & 18.2 & 10.6 & 14.9 \\
\hline \multicolumn{8}{|c|}{ Socioeconomic level } \\
\hline Lower & 28.2 & 26.2 & $33.7^{\star \star \star}$ & 15.1 & $24.6^{* *}$ & $23.8^{*}$ & 15.5 \\
\hline Middle-lower & 20.0 & 23.9 & 21.7 & 13.2 & 17.1 & 13.1 & 28.3 \\
\hline Middle & 32.6 & 24.1 & 20.3 & 18.4 & 13.4 & 14.0 & 18.0 \\
\hline Middle-upper & $43.5^{\star \star \star}$ & 28.7 & 12.1 & $30.4^{\star *}$ & 13.6 & 9.5 & 17.5 \\
\hline \multicolumn{8}{|c|}{ Employment status } \\
\hline Work & $41.3^{\star \star *}$ & 27.7 & 17.3 & 22.7 & 15.9 & 13.3 & 13.9 \\
\hline Housewife & 23.4 & 15.6 & 19.1 & 17.2 & 17.1 & 15.6 & 23.1 \\
\hline Student & 34.9 & 31.7 & 25.5 & $24.0^{\star \star *}$ & 14.6 & 15.1 & 15.5 \\
\hline Unemployed & 28.4 & 37.6 & $28.9^{*}$ & 10.4 & 20.8 & 16.8 & 13.7 \\
\hline Retired & 14.2 & 18.5 & 23.7 & 10.1 & 11.5 & 12.7 & $35.8^{\star \star \star}$ \\
\hline Total & 29.7 & 24.7 & 21.3 & 17.8 & 15.6 & 14.3 & 20.6 \\
\hline EU average & 25.5 & 20.1 & 12.5 & 20.7 & 18.9 & 26.3 & 17.8 \\
\hline
\end{tabular}

Linear trend test (ordinal variables) towards the higher values or Pearson $\chi$-square test (categorical variables): ${ }^{\star} P<0.05,{ }^{\star \star} P<0.01,{ }^{\star \star \star} P<0.001$. 
Table 4 Perceived benefits of healthy eating by Spanish subjects (\%) classified by sex, age group, education level, socioeconomic level and employment status

\begin{tabular}{|c|c|c|c|c|c|c|c|}
\hline & $\begin{array}{l}\text { Prevent } \\
\text { disease }\end{array}$ & $\begin{array}{c}\text { Stay } \\
\text { healthy }\end{array}$ & $\begin{array}{l}\text { Good quality } \\
\text { of life }\end{array}$ & $\begin{array}{l}\text { Control } \\
\text { weight }\end{array}$ & Be fit & $\begin{array}{l}\text { Live } \\
\text { longer }\end{array}$ & $\begin{array}{c}\text { None of } \\
\text { these }\end{array}$ \\
\hline \multicolumn{8}{|l|}{$\overline{S e x}$} \\
\hline Male & 70.4 & 65.5 & 52.2 & 45.2 & $43.8^{* *}$ & 29.7 & 1.2 \\
\hline Female & $76.7^{*}$ & 73.0 & 49.7 & 48.8 & 35.3 & 27.7 & 1.9 \\
\hline \multicolumn{8}{|l|}{ Age (years) } \\
\hline $15-34$ & 70.3 & 66.0 & 53.2 & 49.7 & 45.8 & 24.1 & 1.1 \\
\hline $35-54$ & 72.6 & 62.5 & 57.8 & 40.5 & 35.5 & 28.1 & 1.4 \\
\hline$>55$ & 76.1 & 75.8 & 50.2 & $57.4^{\star}$ & $47.8^{* *}$ & 30.6 & 1.6 \\
\hline \multicolumn{8}{|l|}{ Educational level } \\
\hline Primary & 74.1 & $73.9^{* * *}$ & 46.0 & 46.6 & 36.2 & 30.9 & 1.8 \\
\hline Secondary & 70.8 & 60.9 & 54.3 & 51.1 & 47.6 & 23.0 & 1.7 \\
\hline University & 75.9 & 60.4 & $69.9^{\star \star *}$ & 42.8 & $42.8^{*}$ & 26.2 & 0 \\
\hline \multicolumn{8}{|c|}{ Socioeconomic level } \\
\hline Lower & 78.9 & $82.6^{* *}$ & 53.8 & 52.2 & 40.4 & $38.4^{*}$ & 0 \\
\hline Middle-lower & 75.6 & 70.0 & 45.5 & 43.5 & 32.4 & 33.2 & 2.8 \\
\hline Middle & 70.9 & 67.7 & 51.0 & 7.2 & 41.0 & 24.8 & 0.4 \\
\hline Middle-upper & 73.6 & 62.8 & 63.0 & 50.6 & 50.1 & 26.0 & 0 \\
\hline \multicolumn{8}{|c|}{ Employment status } \\
\hline Work & 70.6 & 64.4 & 54.1 & 42.9 & 41.1 & 27.1 & 1.9 \\
\hline Housewife & 77.3 & 72.1 & 51.4 & 53.1 & 31.6 & 29.4 & 1.1 \\
\hline Student & 66.6 & 65.0 & 51.4 & $56.9^{* *}$ & 57.4 & 24.9 & 0 \\
\hline Unemployed & 72.7 & 68.7 & 53.0 & 49.5 & 53.5 & 28.8 & 1.1 \\
\hline Retired & 79.6 & $77.8^{*}$ & 43.8 & 40.4 & 27.0 & 32.7 & 2.6 \\
\hline Total & 73.6 & 69.4 & 49.7 & 47.0 & 39.4 & 28.7 & 1.6 \\
\hline EU average & 70.6 & 71.0 & 49.1 & 54.3 & 53.1 & 39.6 & 43.1 \\
\hline
\end{tabular}

Linear trend test (ordinal variables) towards the higher values or Pearson $\chi$-square test (categorical variables): ${ }^{\star} P<0.05,{ }^{\star \star} P<0.01,{ }^{\star \star \star} P<0.001$.

'Prevent disease' (73.6\%), 'Stay healthy' (69.4\%), 'Good quality of life' (49.7\%), 'Control weight' (47.0\%), 'Be fit' (39.4\%), 'Live longer' (28.7\%) and 'Have plenty of energy' (28.2\%). Among EU subjects, the two benefits most frequently mentioned were: 'Stay healthy' (71.0\%) and 'Prevent disease' (70.6\%) (Table 4).

In relation to gender, more females perceived 'Prevent disease' and 'Stay healthy' as the main benefit associated with healthy diet $(P<0.05)$ compared to males.

Across all age groups 'Prevent disease' was the most often mentioned benefit associated with healthy nutrition. However, among older subjects the percentage selecting 'Prevent disease' and 'Live longer' still increased, although there were no statistically significant differences.

With regard to educational level, people with university level education were more likely to select a 'Good quality of life' as one of the main benefits $(P<$ 0.01). In contrast, the concept of 'Stay healthy' was more prevalent in those with primary educational levels $(P<0.001)$ and in those belonging to lower socio-economic levels

The main benefits of healthy eating among retired subjects were 'Prevent disease' (79.6\%) and 'Stay healthy' (77.8\%). The concept of 'Stay healthy' was significantly more prevalent among retired individuals.

When the benefits of healthy eating were compared across the most important perceived barriers (Table 5) it appeared that for most of the main benefits there was not much variation across selected barriers. Most subjects who perceived 'Irregular work hours' as a barrier to a healthy nutrition, reported that a 'Good quality of life' would be the most important benefit

Table 5 Benefits of healthy eating (\%) given by Spanish respondents perceiving different barriers as the most significant

\begin{tabular}{lccccc}
\hline Benefits & $\begin{array}{c}\text { Irregular } \\
\text { work hours }\end{array}$ & Willpower & $\begin{array}{c}\text { Unappealing } \\
\text { food }\end{array}$ & $\begin{array}{c}\text { Busy } \\
\text { lifestyle }\end{array}$ & $\begin{array}{c}\text { No difficulty } \\
\text { Prevent disease }(n=742)\end{array}$ \\
Stay healthy $(n=699)$ & 32.1 & 24.1 & 22.1 & 19.0 & 19.8 \\
Good quality of life $(n=513)$ & 30.4 & 26.8 & 25.7 & 18.4 & 18.5 \\
Control weight $(n=474)$ & 35.9 & 26.4 & 20.8 & 22.6 & 14.7 \\
None of these $(n=15)$ & 31.4 & 29.4 & 25.8 & 0 & 17.5 \\
Total $(n=1009)$ & 0 & 0 & 6.9 & 17.8 & 85.4 \\
\hline
\end{tabular}


from it, although the differences were not statistically significant.

\section{Discussion}

For all those involved in nutrition education or food policy issues it is a priority to determine the barriers that the general public may have or perceive they have when trying to eat healthier diets and the personal benefits that they expect in relation to eating more healthily ${ }^{17}$.

In the present study, a representative sample of the Spanish adult population was studied in order to address these two issues. Care was taken to assure the validity of the methods for subject selection and classification of the collected information. Subject selection was quota-controlled to make the samples nationally representative. In addition, weights were applied for population size when examining the Spanish average results ${ }^{18}$. This survey was conducted as 'omnibus' research, i.e. surveys in which interviewed individuals respond to questionnaires on different topics during the same session. This procedure diminishes the likelihood that participation of subjects was dependent of their attitudes towards a particular topic of the survey. The questionnaire was designed and validated by an international and multidisciplinary team applying standardized procedures for the selection of each question and for the codification of the presented options, however, some bias concerning social desirability may appear ${ }^{18}$.

\section{Barriers}

In this study it could be seen that there was great variability in the different barriers to eating a healthy diet among the Spanish population. Overall, $12.6 \%$ of the subjects stated that they did not want to change their eating habits. This may be due to a lack of knowledge about the potential benefits derived from a healthy diet or because they believed they already eat healthily. Conversely, $20.6 \%$ of the Spanish subjects answered 'No difficulty' in trying to eat healthier, perhaps because they had never tried to eat healthier diets, or the fact that they did not actually understand the meaning of a healthy nutrition must be also considered $^{19}$. This concept of 'healthy eating' was considered in the survey too, and the majority of the Spanish people defined it as a diet with 'more vegetables' as the main description ${ }^{20}$.

Conversely, 'Willpower' was one of the most frequently cited options, so nutrition professionals not only should improve their dietary messages, but they should also put greater emphasis on motivation and show the benefits people can get from changing their diets. By contrast, 'Give up foods' was the most common barrier selected by a European population ${ }^{6}$.
Apart from gender, there were differences in the distribution of responses about perceived barriers according to sociodemographic characteristics ${ }^{21}$. Subjects aged 35-54 years, those with higher socioeconomic level, individuals from university level and subjects who were employed were the ones who more often selected 'Irregular work hours' and 'Busy lifestyle' as the main barriers to trying to eat a healthier diet. It might be because they do not have enough time for food preparation because of their lifestyle and that to cook a healthy meal would take up a lot of their spare time which they perceive as impossible in relation to their jobs or lifestyle.

The youngest age group appeared to be those who more frequently regarded 'Unappealing food' as a problem to healthy nutrition, perhaps because these subjects considered healthy eating as less pleasant to look at and to eat. Thus, nutrition educators considered that this group of people follow a more informal pattern of food choice ${ }^{22}$. It is remarkable that a high percentage of individuals from retired employment status (35.8\%) selected the item 'No difficulty' when they were asked about their barriers to healthy nutrition. This choice may be associated with the finding that older people were less inclined to try to change their dietary habits, therefore they were less likely to report problems concerning healthy diet.

About 25\% of the subjects from lower socioeconomic levels regarded 'Price' as their main difficulty when trying to eat a healthier diet. This may be due to the fact that this group may regard the cost of food as prohibitive to eating a more healthy diet. Thus, it is necessary to ensure that foods which should be included in a healthy diet are not too expensive or perceived as such, and also to assess at subgroup level what the subject's beliefs are about what a better diet should entail ${ }^{23}$.

In a pan-EU study, variability has been demonstrated in the perceived barriers to healthy eating between different EU countries. Lack of time was the most frequently mentioned difficulty among EU subjects for not following nutritional advice (24\% of total EU sample). This barrier was frequently reported by the younger and the higher educated people. Other frequently reported barriers were giving up favourite foods (23\%) and willpower (18\%). Thus healthy diets do not appear to be viewed as an easy or attractive alternative to current diets $^{6}$.

\section{Benefits}

In relation to the benefits derived from eating a healthier diet, only $1.6 \%$ of the respondents cited none of the possible options or 'Don't know'. Therefore, most people believed that healthy eating was associated with at least one benefit.

Females were more likely than males to choose 
'Prevent disease' as a possible benefit, perhaps due to the fact that in nutrition education healthy eating is usually related to protection against chronic diseases and women are the ones who have more interest in this kind of education ${ }^{24}$. The concerns about body shape and weight were other potential benefits perceived among Spanish subjects and both appeared to differ between males and females, women mentioned more frequently 'Control weight' as a healthy eating benefit, while men were more likely to select 'Be fit'. This meant that depending on gender, the perceived benefits would be different perhaps because each group has a different goal or objective in eating a healthy diet ${ }^{25}$.

The percentage of individuals choosing 'Stay healthy' and 'Live longer' as benefits increased with decreasing socioeconomic and educational levels, this decrease might be explained because both social levels may have their personal opinion about what healthy diet means, while people from higher status have another point of view about healthy nutrition such as 'Good quality of life ${ }^{26}$.

Within the EU the perceived benefits of healthy eating vary across countries. This may be because of differing food intakes and meal patterns across countries. So, a standardized EU nutrition policy may not be equally effective in all member states. In that study, $31 \%$ of subjects stated 'stay healthy', $24 \%$ 'prevent disease', $10 \%$ 'control weight', $10 \%$ 'quality of life' and $9 \%$ 'be fit' as the main benefits of a healthy $\operatorname{diet}^{7}$. In this context, any nutritional advice which is given needs to be perceived as achievable within the subject's lifestyle in an educational and social context and also perceived as compatible with regard to the tasteful aspects of food particularly for young individuals $^{27,28}$. In addition, nutrition educators and food policy makers should try to ensure that nutritious and healthy foods are not expensive ${ }^{29}$. Specialists need to be aware of how the population believes they can benefit from changing their diets, and so to develop their campaigns to encourage more people to alter their eating habits in the direction of nutrition goals ${ }^{30}$.

Nutrition educators should always be aware that the main perceived barriers of healthy eating are included in the following factors: an irregular and busy lifestyle, willpower and food-related factors (high prices, unappealing meals). These findings must be taken into account for designing more relevant nutritional messages and for addressing them to different target groups in Spain. Conversely, the aspects related to prevention of disease and promotion of health comprised the main perceived benefits for the Spanish population.

\section{Acknowledgements}

The financial support from IEFS from Ireland is gratefully acknowledged.

\section{References}

1 McGinnis JM, Hamburg MA. Opportunities for health promotion and disease prevention in the clinical setting. West. J. Med. 1988; 149: 468-74.

2 Serra-Majem Ll, Ribas M. Hábitos alimentarios y consumo de alimentos en España. Dieta mediterránea. In: Serra-Majem Ll, Araceta J, Mataix J (eds) Nutrición y Salud Pública. Métodos, Bases Científicas y Aplicaciones. Barcelona: Masson, 1995: 303-10.

3 Trichopoulou A, Lagiou P. Healthy traditional Mediterranean diet: an expression of culture, history, and lifestyle. Nutr. Rev. 1997; 55: 383-9.

4 Baghurst KI. Food consumption patterns in an affluent society and barriers to overcoming dietary change. Ann. Acad. Med. Singapore 1992; 21: 145-51.

5 Sparks P, Shepherd R, Wieringa N, Zimmermmans N. Barriers to healthy eating: an examination of perceived behavioural control and unrealistic optimism. Appetite 1994; 23: 290.

6 Lappalainen R, Saba A, Holm L, Mykkanen H, Gibney MJ. Difficulties in trying to eat healthier: descriptive analysis of perceived barriers for healthy eating. Eur. J. Clin. Nutr. 1997; 51 (suppl. 2): S36-40.

7 Zunft HJF, Friebe D, Seppelt B, de Graaf C, Margetts B, Schmitt A, Gibney MJ. Perceived benefits of healthy eating among a nationally-representative sample of adults in the European Union. Eur. J. Clin. Nutr. 1997; 51 (suppl. 2): S416.

8 Almeida MDV, Graca P, Lapplainen R et al. Sources used and trusted by nationally-representative adults in the European Union for information on healthy eating. Eur. J. Clin. Nutr. 1997; 51 (suppl. 2): S16-22.

9 Serra-Majem-Ll, Ribas L, Tresserras $\mathrm{R}$ et al. How could changes in diet explain changes in coronary heart disease mortality in Spain? The Spanish paradox. Am. J. Clin. Nutr 1995; 61 (suppl. 6): 1351-9.

10 Varela G, Carbajal A, Nuñez C et al. Influencia de la ingesta energética y del índice de masa corporal en la incidencia del cáncer de mama. Estudio caso-control en una muestra procedente de tres poblaciones hospitalarias españolas. Nutr. Hosp. 1996; 11 (suppl. 1): 54-8.

11 Varela G, Moreiras-Varela O, Carbajal A et al. Estudio transversal entre la cantidad y calidad de la grasa consumida en España y la mortalidad por diferentes tipos de neoplasias del aparato reproductor. Rev. Clin. Esp. 1991; 189: 55-9.

12 Adams LB. An overview of adolescent eating behaviour barriers to implementing dietary guidelines. Ann. NY Acad. Sci. 1997; 817: 36-48.

13 IEFS. A pan EU Survey of Consumer Attitudes to Food, Nutrition and Health. Institute of European Food Studies. Dublin, IEFS, 1996: 1-29.

14 Margetts BM, Martínez JA, Saba A, Holm L, Kearney M. Definition of 'healthy eating', a pan EU Survey of consumer attitudes to food, nutrition and health. Eur. J. Clin. Nutr. 1997; 51 (suppl. 2): S23-9.

15 Kearney M, Kearney JM, Gibney MJ. Methods used to conduct the survey on consumer attitudes to food, nutrition and health on nationally representative samples of adults of each member state from the European Union. Eur. J. Clin. Nutr. 1997; 51: S3-7.

16 Comunidad de Madrid. Consejería de Economía. Censos de Población y Vivienda de 1991 de la Comunidad de Madrid. Tomo I: Características demográficas básicas y fecundidad de la población. Madrid: Consejería de Economía, 1993.

17 Glanz K, Mullis RM. Environmental interventions to promote healthy eating: a review of models, programs, and evidence. Health Educ. Q. 1988; 15: 395-415.

18 Barnett V. Sample Survey: principles and methods. London: Arnold, 1991.

19 Kushner RF. Barriers to providing nutrition counselling by 
physicians: a survey of primary care practitioners. Prev. Med. 1995; 24: 543-5.

20 Martínez-González MA, López-Azpiazu I, Kearney J, Kearney M, Gibney M, Martínez JA. Definition of healthy eating in the Spanish population: a national sample in a panEuropean survey. Publ. Health 1998; 112: 1-7.

21 Prevost AT, Wichelow MJ, Cox BD. Longitudinal dietary changes between 1984-5 and 1991-2 in British adults: associations with sociodemographic, lifestyle and health factors. Br. J. Nutr. 1997; 78: 873-88.

22 Moreiras-Varela O, Carbajal A. Determinantes socioculturales del comportamiento alimentario de los adolescentes. An. Esp. Pediatr. 1992; 36 (suppl. 49): 102-5.

23 Bolton-Smith C, Smith WCS, Woodward M, Tunstall-Pedoe H. Nutrient intakes of different social-class groups: results from the Scottish Heart Health Study. Br. J. Nutr. 1991; 65: 321-35.

24 López-Azpiazu I, Martínez-González MA, Gibney M, Kearney J, Kearney M, Martínez JA. Factores con mayor influencia en la elección de los alimentos en la población española. Rev. Esp. Nutr. Comun. 1997; 3: 113-21.
25 López Nomdedeu C. Cuándo y cómo educar en nutrición. Unas reflexiones sobre Educación Nutricional. Alim. Nutri. Salud. 1997; 4: 110-13.

26 Smith AM, Baghurst KI. Public health implications of dietary differences between social status and occupational category groups. J. Epidemiol. Comm. Health. 1992; 46: 409-16.

27 Buttriss JL. Food and nutrition: attitudes, beliefs; and knowledge in the United Kingdom. Am. J. Clin. Nutr. 1997; 65 (suppl. 6): S1985-95.

28 Paisley C, Lloyd H, Sparks P, Mela DJ. Consumer perceptions of dietary changes for reducing fat intake. Nutr. Res. 1995; 15: $1755-66$.

29 Ortega RM, Andrés P, Melendez A. Influencia de la nutrición en la capacidad funcional de un grupo de ancianos españoles. Arch. Latinoam. Nutr. 1992; 42 (suppl. 2): $133-45$.

30 Willett WC, Sacks F, Trichopoulou A, Drescher G, FerroLuzzi A, Helsing E, Trichopoulos D. Mediterranean diet pyramid: a cultural model for healthy eating. Am. J. Clin. Nutr. 1995; 61 (suppl. 6): S1402-6. 